\title{
Characterization of epithelial cell shedding from human small intestine
}

Tim F Bullen ${ }^{1}$, Sharon Forrest ${ }^{2}$, Fiona Campbell ${ }^{2}$, Andrew R Dodson ${ }^{2}$, Michael J Hershman ${ }^{3}$, D Mark Pritchard ${ }^{1}$, Jerrold R Turner ${ }^{4}$, Marshall H Montrose ${ }^{5}$ and Alastair JM Watson ${ }^{1}$

\begin{abstract}
${ }^{1}$ Division of Gastroenterology, School of Clinical Sciences, University of Liverpool, Liverpool, UK; ${ }^{2}$ Department of Pathology, Royal Liverpool University Hospital Trust, Liverpool, UK; ${ }^{3}$ Department of Surgery, Royal Liverpool University Hospital Trust, Liverpool, UK; ${ }^{4}$ Department of Pathology, The University of Chicago, Chicago, IL, USA and ${ }^{5}$ Department of Molecular \& Cellular Physiology, University of Cincinnati, Cincinnati, $\mathrm{OH}, \mathrm{USA}$
\end{abstract}

\begin{abstract}
Intestinal epithelial cells migrate from the base of the crypt to the villi where they are shed. However, little is known about the cell shedding process. We have studied the role of apoptosis and wound healing mechanisms in cell shedding from human small intestinal epithelium. A method preparing paraffin sections of human small intestine that preserves cell shedding was developed. A total of 14417 villus sections were studied. The relationship of cell shedding to leukocytes (CD45), macrophages (CD68) and blood vessels (CD34) were studied by immunohistochemistry. Apoptotic cells were identified using the M30 antibody against cleaved cytokeratin 18 and an antibody against cleaved caspase-3. Potential wound healing mechanisms were studied using antibodies against Zona Occludens-1 (ZO-1) and phosphorylated myosin light chains (MLCs). We found that $5.3 \%$ of villus sections contained a shedding cell. An eosin-positive gap was often seen within the epithelial monolayer beneath shedding cells. Shedding was not associated with leukocytes, macrophages or blood vessels. Cells always underwent apoptosis during ejection from the monolayer. Apoptotic bodies were never seen in the monolayer but morphologically normal cells that were positive for M30 or cleaved caspase-3 were often seen. ZO-1 protein was usually (41/42) localized to the apical pole of cells neighboring a shedding event. Phosphorylated MLCs could be identified in $50 \%$ of shedding events. In conclusion, cell shedding is associated with apoptosis though it remains unclear whether apoptosis initiates shedding. It is also associated with phosphorylation of MLCs; a process associated previously with wound healing.

Laboratory Investigation (2006) 86, 1052-1063. doi:10.1038/labinvest.3700464; published online 14 August 2006
\end{abstract}

Keywords: colorectal; intestine; apoptosis; epithelial; human; immunohistochemistry

In human, intestinal epithelial cells migrate from the base of the crypt to the villi where approximately $10^{10}$ cells are shed per day., ${ }^{1,2}$ This phenomenon was first described in 1948 and the term 'extrusion zone' coined to denote the area on the villus or colonic surface where cells are lost., Although cell shedding has been frequently quantified, little is known about the mechanism(s) mediating cell shedding. ${ }^{5-8}$

A number of mechanisms for cell shedding have been proposed (for review see Mayhew et $a l^{9}$ ). In mouse and possibly humans the whole cell is shed and then subsequently undergoes apoptosis (anoi-

Correspondence: Professor AJM Watson, MD, School of Clinical Sciences, The Henry Wellcome Laboratory, Nuffield Building, University of Liverpool, Crown Street, Liverpool L69 3BX, UK. E-mail: Alastair.watson@liv.ac.uk

Received 3 June 2006; revised and accepted 10 July 2006; published online 14 August 2006 kis) as attachments to the basement membrane are loosened. ${ }^{10-12}$ In the guinea-pig, apoptotic fragments are pinched off leaving junctional complexes intact. Remarkably nuclei are rarely found in the lumen. ${ }^{13}$ In reindeer and seals, cell fragments are lost from the villus either by extrusion or phagocytosis by neighboring macrophages. There is also evidence of necrotic cell death at the villus tip in these species with breach of the epithelial monolayer. ${ }^{14}$ It has also been suggested that apoptosis or anoikis initiates cell shedding although direct evidence is sparse and mice lacking bcl-2, bcl-w or bax have apparently normal villus architecture. ${ }^{15-18}$ The mechanism of cell shedding is important because abundant shedding must be achieved without loss of intestinal barrier function. Classically, the epithelial barrier is believed to have two parts. One component is the intrinsic impermeability of the epithelial cell apical membrane. The second is the tight junction between adjacent epithelial cells, which 
restricts paracellular flux between cells. ${ }^{19,20}$ Our own work using in vivo confocal and two-photon microscopy of living intestinal tissue from mice, suggests that there is a third component of the epithelial barrier that may also be important for controlling passive permeability. We observe that an impermeable substance plugs epithelial discontinuities on the villus following cell shedding, resulting in $3 \%$ of surface area that have such gaps near the villus tip. ${ }^{12}$ Studies in human tissue culture models show that recovery from physical wounding involves sequential activation of rho kinase (ROCK) and myosin light chain kinase (MLCK) leading to contraction of an actin ring, like a purse string, that closes off the denuded region and restores barrier function. ${ }^{21-24}$ As cell loss leaves a defect in the epithelium that ultimately has to be healed, we hypothesize that epithelial gaps caused by cell shedding may be healed by mechanisms similar to those that heal epithelial wounds.

In this study, we have developed and applied a routine method for obtaining human histological sections in which cell shedding can readily observed and characterized. We use the preparation to examine biochemical features of apoptosis and activation of MLCK and found that the gaps left after cell shedding are healed by a mechanism akin to wound healing of cultured epithelial monolayers.

\section{Materials and methods}

\section{Subjects}

A total of 14417 villus sections were studied from six individuals (aged 24-78 years; two male and four female) who underwent ileal resection for malignancy (three cases), reversal of ileostomy (two cases) and ulcerative colitis (one case). The tissue obtained was at least $5 \mathrm{~cm}$ distant to any pathological lesions present. The study had ethical approval (04/Q1505/ 135 Date: 21 December 2004) and informed consent was obtained from all participants.

\section{Tissue Collection and Fixation}

Standard surgical resections were undertaken with the exception that vessels supplying the small bowel were ligated last. Resected tissue was taken immediately to the pathology department (longest time $<25 \mathrm{~min}$ ) and carefully placed in either $10 \%$ neutral buffered formalin (BIOS Europe Ltd, Skelmersdale, UK) or a mixture of three parts methanol and one part acetic acid for fixation. Following fixation specimens were embedded in paraffin and $4 \mu \mathrm{m}$ sections taken. Sections were stained with hematoxylin and eosin (H\&E) and the number of shedding events counted. We compared a variety of tissue preparation methods for fixation to optimize preservation of cell shedding events (Figure 1). We found that simply slicing bowel across its long axis into $5-10 \mathrm{~cm}$ segments before placing in neutral buffered formalin was the best technique (Figure 1a), presumably because this minimized the shear forces at the luminal surface during handling and fixation. Care was always taken to ensure the specimen was completely covered with formalin for $48 \mathrm{~h}$. Pinning the specimen to a corkboard provided the best preservation. However, the number of cells seen in the process of being shed was reduced compared to the other fixation methods tried; presumably due to shear forces removing the shedding cells from the epithelium (Figure 1e). The other methods did not achieve adequate preservation of cell shedding events.

\section{Histological Assessment and Immunohistochemistry}

Tissue sections were stained using standard histological techniques with $\mathrm{H} \& \mathrm{E}$ or a combination of periodic acid Schiff and Alcian Blue (ABPAS). ${ }^{25}$

For immunohistochemistry, paraffin sections were dewaxed in xylene and rehydrated in graded ethanol to distilled water. Endogenous peroxidase activity was blocked using $3 \%$ hydrogen peroxide in methanol for $12 \mathrm{~min}$, and then sections were washed in deionized water for $5 \mathrm{~min}$. Sections undergoing heat-mediated antigen retrieval were placed in a pressure cooker filled with $10 \mathrm{mM} / \mathrm{l}$ EDTA (pH 7.0) and treated at full pressure for $3 \mathrm{~min}$. All sections were stained in a DakoCytomation Autostainer.

Primary antibody was applied for $40 \mathrm{~min}$, then sections were washed and incubated with the DakoCytomation ChemMate EnVision Detection Kit (Catalogue no. K5007, DakoCytomation, Ely, UK). Labelled polymer detection agent was applied for $30 \mathrm{~min}$ at room temperature followed by the DAB + chromogen for $20 \mathrm{~min}$ at room temperature. Between each step, sections were washed in Tris-buffered saline. Sections were counterstained with hematoxylin, dehydrated in graded alcohol followed by xylene and mounted in DPX. Negative controls were performed using antibody diluent in place of an antibody.

The following primary antibodies were used: Rabbit cleaved caspase-3 antibody (dilution 1:200$0.3 \mu \mathrm{g} / \mathrm{ml}$ ) (catalogue no. \#9661; Cell Signalling Technology, MA, USA); ${ }^{26}$ Rabbit Zona Occludens-1 antibody (ZO-1) (dilution one in $100-2.5 \mu \mathrm{g} / \mathrm{ml}$ ) (catalogue no. 61-7300; Zymed Laboratories Inc., San Francisco, CA, USA); Phosphorylated myosin light chain (MLC) antibody (dilution one in 80$10 \mu \mathrm{g} / \mathrm{ml}$ ). This antibody is active solely against phosphorylated MLCs. ${ }^{27}$ Monoclonal mouse antiHuman CD34 antibody (dilution 1:50-1 $\mu \mathrm{g} / \mathrm{ml}$ ) (catalogue no. M 7165; DakoCytomation, Ely, UK); Monoclonal mouse anti-Human CD45 antibody (dilution 1:2000-0.16 $\mu \mathrm{g} / \mathrm{ml}$ ) (catalogue no. M 0701; DakoCytomation, Ely, UK); Monoclonal mouse anti-Human CD68 clone PG-M1antibody (dilution 1:200-0.625 $\mu \mathrm{g} / \mathrm{ml}$ ) (catalogue no. M 0876; DakoCytomation, Ely, UK). 

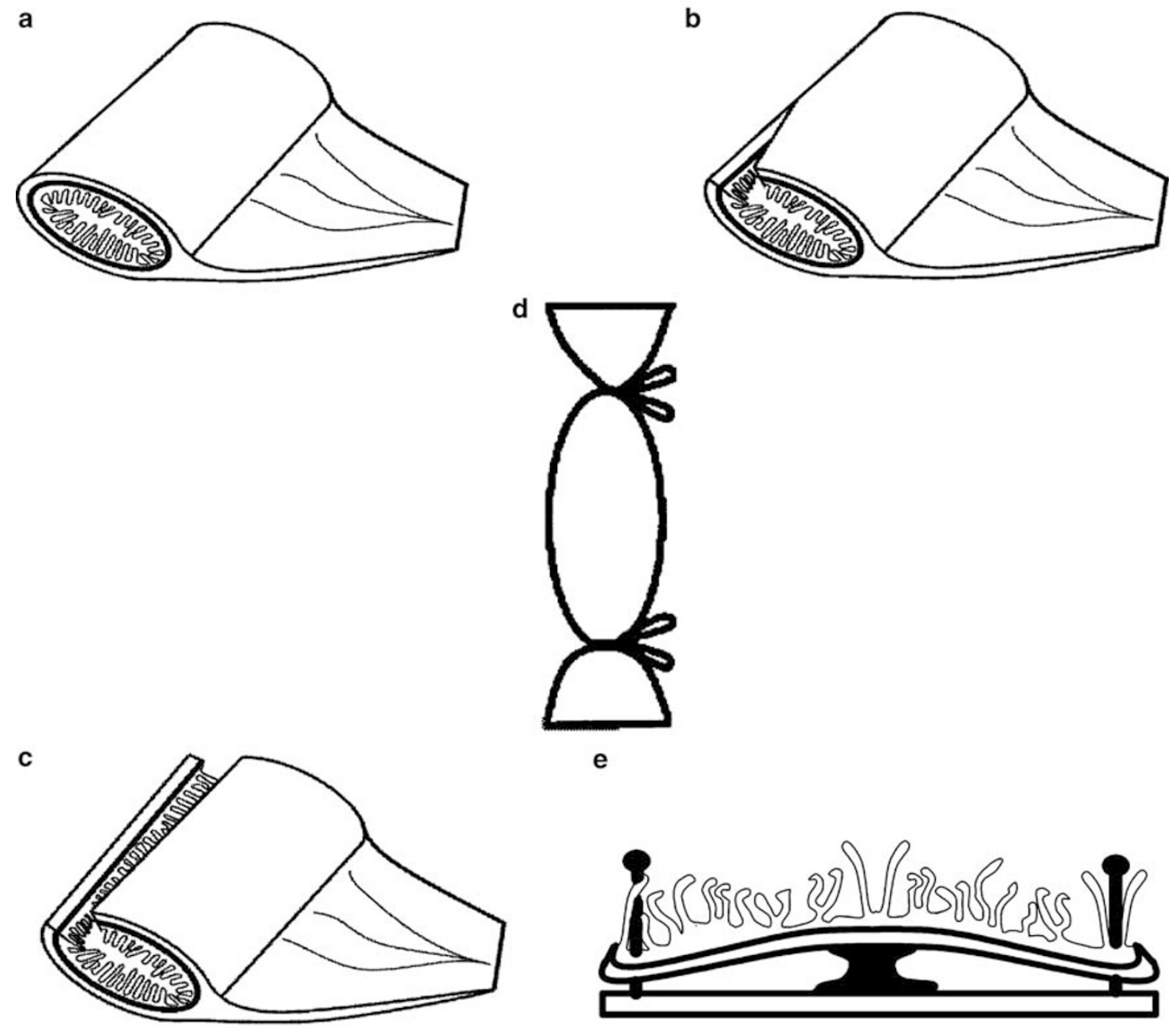

Figure 1 Techniques of bowel exposure to fixative to preserve cell shedding events. (a) Bowel placed directly in neutral buffered formalin for $48 \mathrm{~h}$ with no intervention. (b) A half-length slit was made in the antimesenteric border of the bowel. (c) A full-length slit was made in the antimesenteric border of the bowel. (d) The bowel was inflation fixed by filling with neutral buffered formalin for $48 \mathrm{~h}$ and tying off the ends of the intestinal segment and (e) the bowel was pinned flat to a corkboard and inverted in neutral buffered formalin for $48 \mathrm{~h}$.

\section{Double Immunostaining}

For immunofluorescent double staining, serial $3 \mu \mathrm{m}$ paraffin sections were dewaxed in xylene and rehydrated in graded ethanol to distilled water. Heat-mediated antigen retrieval was performed in a pressure cooker filled with $10 \mathrm{mM} / \mathrm{l}$ EDTA (pH 7.0) in which sections were treated at full pressure for 3 min. Manual staining was undertaken in a flat-bed incubation tray.

Primary antibodies were applied for $60 \mathrm{~min}$ following which sections were washed in TBS and incubated for $60 \mathrm{~min}$ with a mixture of two fluorescently labelled secondary antibodies: FITC-labelled horse anti-mouse IgG (dilution 1:50-30 $\mu \mathrm{g} / \mathrm{ml}$ ) (Catalogue no. Fl-2000; Vector Laboratories, Peterborough, UK), and TRITC-labelled swine anti-rabbit Igs (dilution 1:50-25 $\mu \mathrm{g} / \mathrm{ml}$ (Catalogue no. R0156; DakoCytomation, Ely, UK). Sections were washed in
TBS and mounted in aqueous mounting medium containing DAPI (Catalogue no. H-1200; Vector Laboratories, Peterborough, UK). Negative controls were performed using antibody diluent in place of antibody.

The following primary antibodies were applied singly and concurrently as a mixture to serial sections: rabbit anticleaved caspase-3 antiserum (dilution 1:50-1.2 $\mu \mathrm{g} / \mathrm{ml}$ ) (catalogue no. \#9661; Cell Signalling Technology, MA, USA): mouse anticleaved cytokeratin 18 antibody, clone $\mathrm{M}^{28}{ }^{28}$ (dilution 1:50-0.66 $\mu \mathrm{g} / \mathrm{ml}$ ) (Catalogue no. 2140349; Roche Applied Sciences, Penzberg, Germany).

\section{Statistical Analysis}

Analysis of categorical data was undertaken by $\chi^{2}$ testing. 


\section{Results}

When the small intestine was fixed as described in Materials and Methods, cells in the process of being shed could be readily seen and assessed (Figure 2). We found 771 shedding cells from 14417 villus sections $(5.35 \%)$ with all stains. Shedding cells were identified and defined as cells with a nucleus oriented beyond the apical membrane boundary of neighboring cells. In shedding cells, the apical membrane appears to be more prominent than its neighbors, and the nuclear chromatin becomes condensed and fragments before falling off into the lumen. The cytoplasm does not obviously fragment but appears to shed largely intact. Beneath the shedding cell there is an area of reduced eosin staining that does not contain a nucleus (Figure 2d and e). These zones appear to be the histological equivalent of the epithelial gaps we have observed by confocal microscopy in the living mouse intestine. ${ }^{12}$

We then characterized the cellular environment of the shedding cells. We were able to readily distinguish shedding epithelial cells from intraepithelial lymphocytes by immunostaining against CD45 (leukocyte common antigen) (Figure $3 \mathrm{~b}$ ). There is no evidence that leukocytes cluster around shedding cells. In $27 / 73(37 \%)$ shedding events there was a leukocyte within one nucleus distance from the estimated site of origin of the shedding cell. Conversely, 48/104 (46\%) nonshedding epithelial cells within the monolayer had a leukocyte within the same distance. Staining with ABPAS demonstrated that the material beneath shedding cells is not acid or neutral mucin and can be easily distinguished from goblet cells (Figure 3a). In the guinea-pig, it has been reported that macrophages phagocytose effete cells at the villus tip. ${ }^{13}$ We find no evidence for such a mechanism in our human samples. CD68 + ve macrophages were observed within a distance of one nucleus of 24/36 (67\%) shedding cells and 54/70 (77\%) of nonshedding cells (Figure 3c). The signal initiating cell shedding is unknown. It is plausible that shedding may only occur when the epithelial cell passes over a blood vessel where there may be high local concentrations of a signalling substance or that substances inhibitory to shedding diminish as cells become distant to vessels (eg Netrin-1). ${ }^{29}$ We find little evidence for this as shedding and nonshedding epithelial cells had a similar frequency within a $10 \mu \mathrm{m}$ radius of a CD34 + ve blood vessel (43/47 (91\%) vs 84/92 (91\%), respectively) (Figure $3 \mathrm{~d}$ ).

\section{Apoptosis and Cell Shedding}

Intestinal villus epithelial cells which have become detached from the basement membrane undergo a phenomenon known as anoikis (detachmentinduced apoptosis). ${ }^{30,31}$ However, the relationship of anoikis to physiological cell shedding is not known. We investigated whether or not epithelial cells undergo apoptosis before detaching from the epithelial monolayer with only late stage apoptotic bodies being shed. We defined apoptotic cells as those with immunopositive activated caspase-3 throughout the cytoplasm. ${ }^{26}$ Of 342 cells undergoing shedding only one were negative for activated caspase-3. Cells fragment into apoptotic bodies during shedding with only a few small apoptotic fragments remaining in the epithelial monolayer (Figure 4a and b). It is possible that these retained apoptotic fragments are not derived from epithelial cells but from lymphocytes, fibroblasts or other cells types. Apoptotic bodies from epithelial cells were never seen in the villus epithelium. This is in sharp contrast to the crypt where apoptotic bodies are retained within the epithelial monolayer (Figure 4c).

We have observed previously that adjacent epithelial cells are sometimes shed sequentially as sheets (Watson et $a l^{12}$ and data not shown). We were therefore interested to determine whether or not the morphologically normal epithelial cells adjacent to shedding cells contain activated caspase-3. Of the 342 shedding cells, 26 had caspase-3-positive neighbors that were not being shed and were otherwise morphologically normal (Figure 4b). We speculate that these cells were caught directly before initiating cell shedding. It seems likely that initiation of cell shedding and activation of apoptosis pathways occur at approximately the same time.

To distinguish epithelial cells from other cell types we used the M30 monoclonal antibody which detects the Asp396 caspase cleavage site in cytokeratin $18 .^{32}$ Using double staining immunofluorescence we identified 69 shedding cells. Of these cells, 45 were stained for both caspase-3 and M30 (Figure $4 \mathrm{~d}$ and g). Of them, 19 shedding cells were positive for M30 but negative for caspase-3 (Figure $4 \mathrm{e}$ and $\mathrm{f}$ arrows). Conversely, five cells were positive for caspase-3 and negative for M30 (Figure 4g solid arrow). There was no statistical difference in the proportion of cells positive for either caspase-3 or M30. Sometimes shedding cells were observed on the shaft, rather than the tip, of the villus (Figure 4e and f). Overall, these results confirm that epithelial cells are undergoing apoptosis during the process of shedding. However, no firm conclusion can be drawn from these data whether apoptosis precedes or follows the initiation of cell shedding.

\section{ZO-1 and Phosphorylated MLC Localization after Cell Shedding}

Tight junctions must be disturbed in order for a cell to be shed. Madara ${ }^{33}$ has proposed that lamellipodia from neighboring cells extend beneath the shedding cell and form a tight junction, which then rises behind the shedding cell. Alternatively, the epithelial gaps remaining after cell shedding may be 

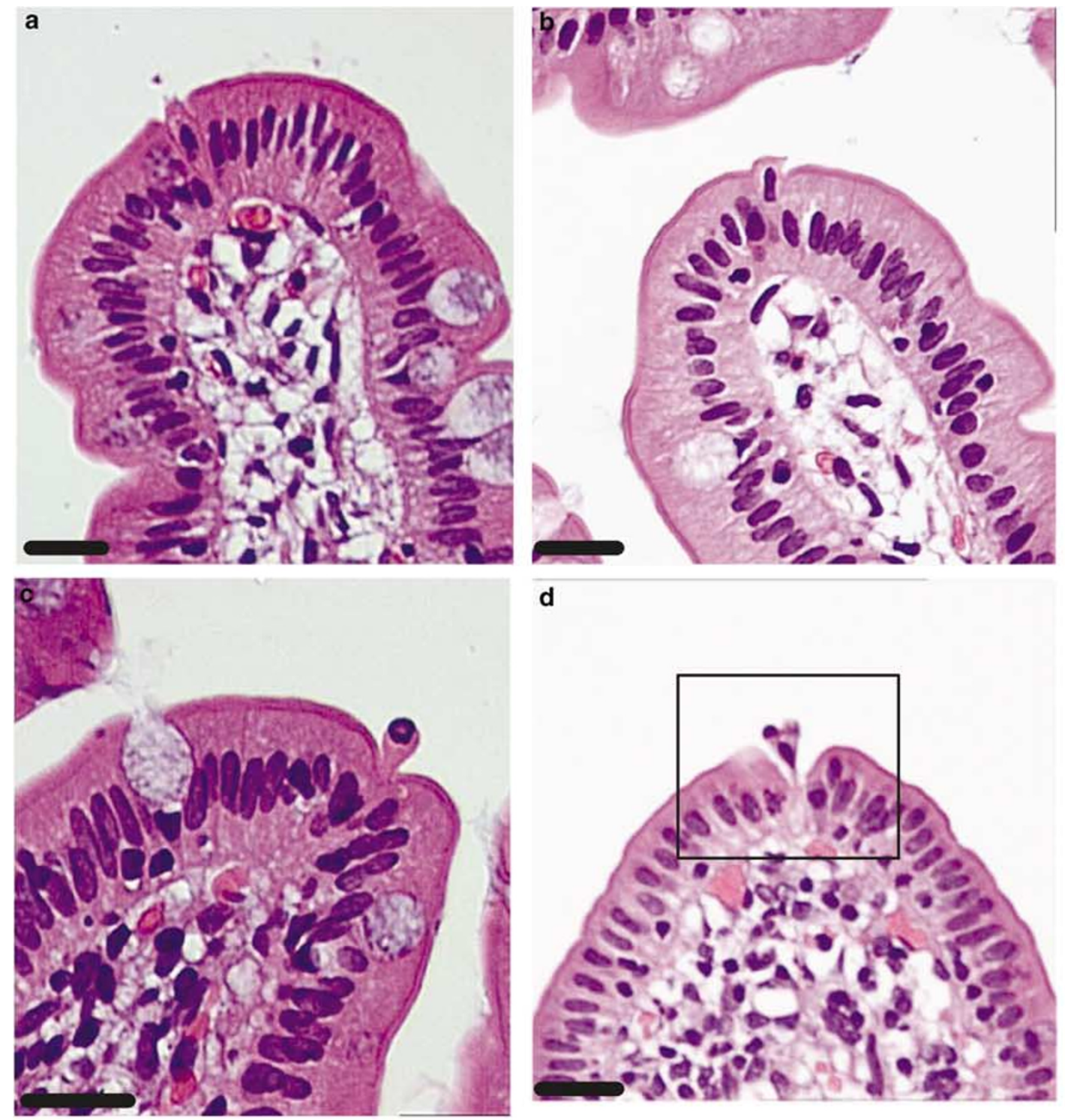

d
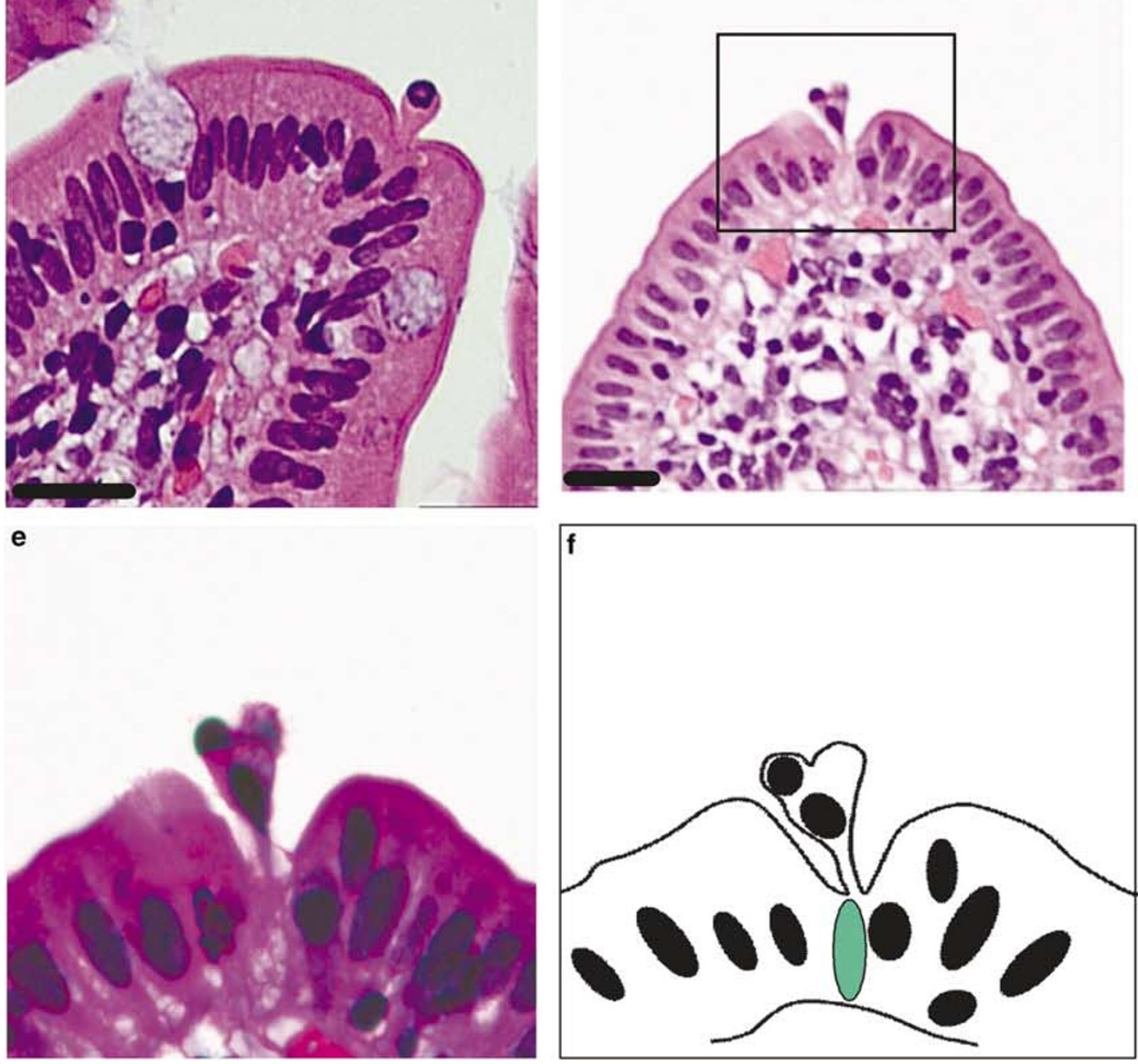

Figure 2 Morphology of small intestinal epithelial cells during the process of shedding. Four examples of cells (a-d) are shown as they progress through the process of shedding. The nuclei become progressively more pyknotic and fragmented as shedding progresses. Eosin staining is reduced beneath the shedding cell in (d) and highlighted green in the line drawing (f). This is extending from the level of neighboring nuclei to the basement membrane. A magnification of image (d) is shown in (e). 

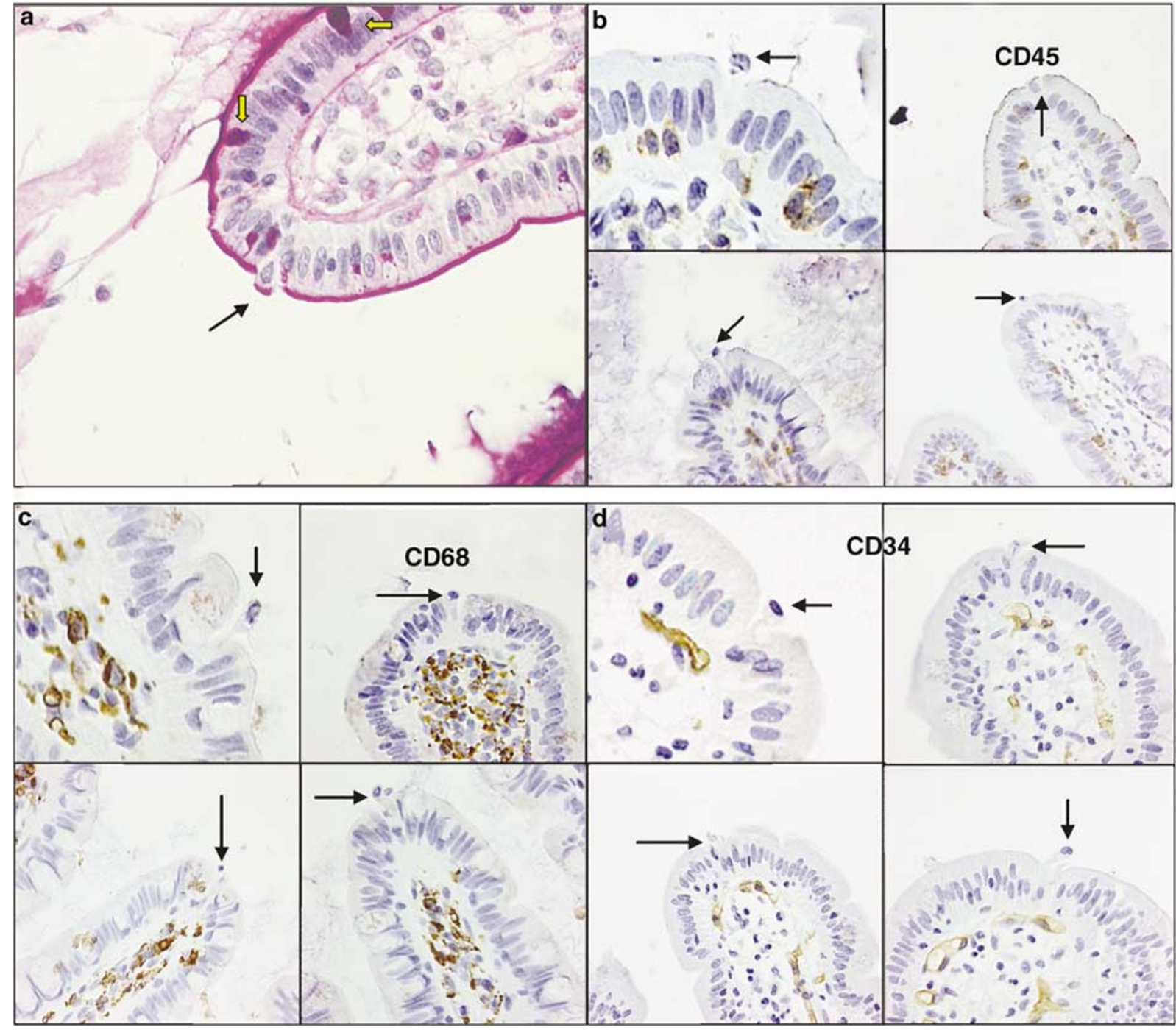

Figure 3 Characterization of the environment of epithelial cells during shedding. (a) There is no evidence of mucus (acid/neutral) beneath shedding cells (arrow). Shedding events can be readily distinguished from goblet cells (block arrows). There is no clustering of (a) CD45 + ve leukocytes or (c) CD68 + ve macrophages around shedding cells. (d) Blood vessels identified by the CD34 endothelial marker can sometimes be found near shedding epithelial cells. Arrows indicate shedding cells.

healed by mechanisms similar to those that heal oligocellular wounds. ${ }^{22,24}$ Here, the actin ring at the apical pole of cells at the edge of the wound contracts like a purse-string contracture. In this model the tight junction remains at the apical pole of cells. We used a monoclonal antibody against ZO1 to investigate the site of tight junction formation in association with cell shedding. The majority of shedding cells in the human small intestine had ZO-1 activity at the apical pole (41/42) (Figure 5a) as opposed to the basal pole (1/42) (Figure 5b).

MLCs become phosphorylated during healing of oligocellular wounds. ${ }^{24}$ We asked if phosphorylated MLCs could be detected at the edges of gaps left after cell shedding. We used a rabbit polyclonal antibody against phosphorylated MLCs to identify whether this mechanism was involved in cell shedding. ${ }^{27}$ Over half the small intestinal shedding events studied demonstrated phosphorylated MLC activity (25/46) (Figure 6a-d). This indicates that phosphorylated myosin light-chains are commonly present in neighboring cells during cell shedding and suggests that mechanisms associated with epithelial wound healing participate in intestinal epithelial cell shedding. ${ }^{20,24}$

\section{Discussion}

There are few studies, if any, in the literature describing the morphology of human epithelial cells during the process of shedding from small intestinal villi. This is an especially striking omission given the high rate of cell renewal along the crypt/villus axis. ${ }^{1}$ We reasoned that shear forces and delays during the preparation of standard histological 

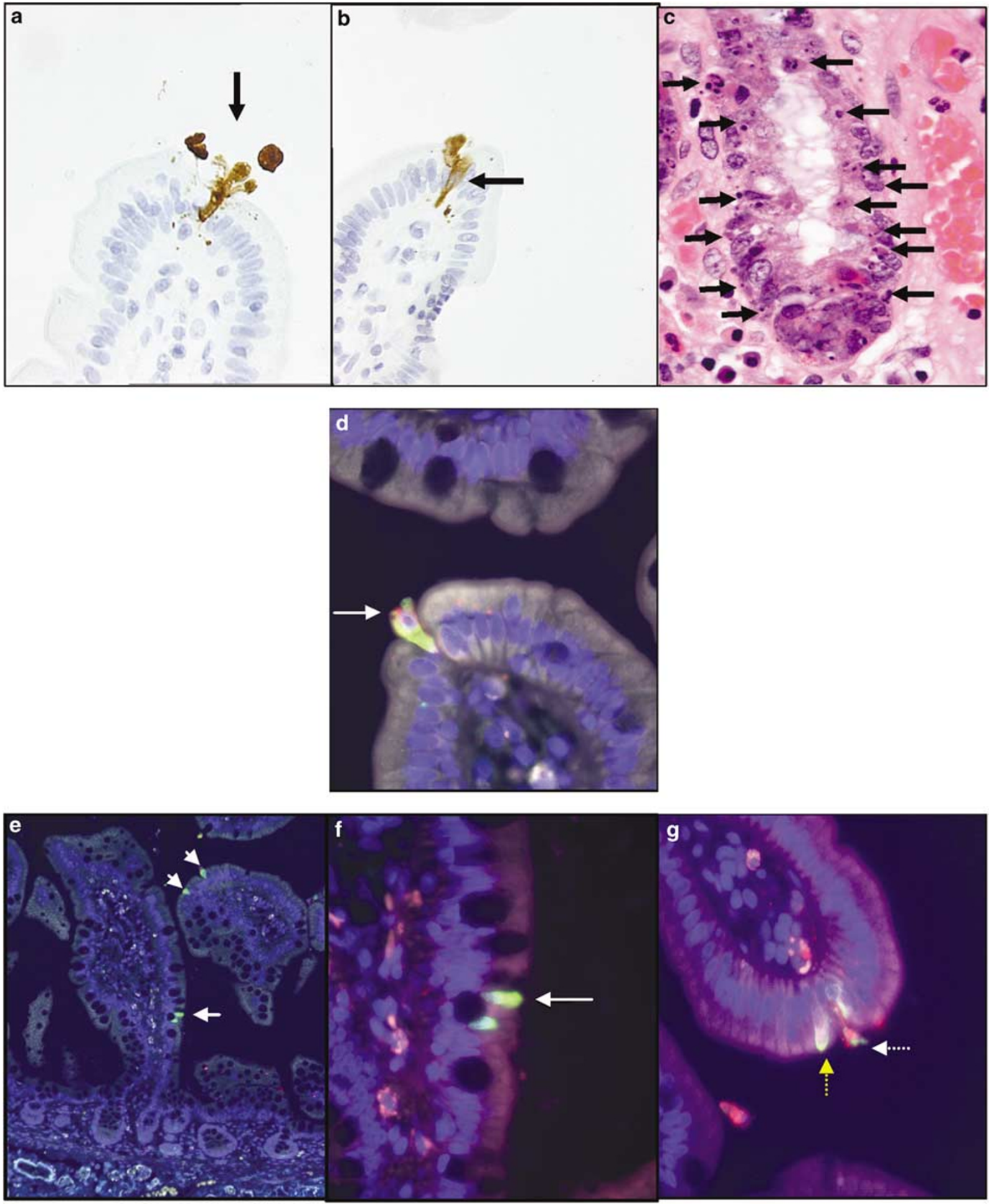

Figure 4 Apoptosis and cell shedding. (a) An apoptotic cell with activated caspase- 3 throughout the cytoplasm and nucleus in the process of being shed. Note the base of the cell is above the lower limit of the neighboring nuclei and the majority of caspase-3-positive material is ejected into the intestinal lumen, however, a minority is visible within the lamina propria. (b) A cell (vertical arrow) in the process of being shed from a villus tip and a second (horizontal arrow) with activated caspase-3 that does not appear to be shedding but appears attached to the basement membrane. (c) Human small intestinal crypts from a patient with radiation enteritis. Arrows indicate apoptotic bodies within the epithelial monolayer. (d-g) Images of cell shedding event stained by double immunofluorescence for M30 (green) and cleaved caspase-3 (red). Colocalization of immunostaining for the two antibodies is yellow. (d) Shows a cell in the process of being shed, which contains areas of colocalization of immunostaining for the two antibodies (arrow). (e and f) Low and high power images of the same sections showing an example of cell shedding from the shaft of the villus. The shedding cells are positive for M30 and negative for caspase-3. (g) Shows a caspase-3-postive cell being shed (solid arrow). It neighbor in the monolayer (dotted arrow) is positive for both M30 and caspase-3. 

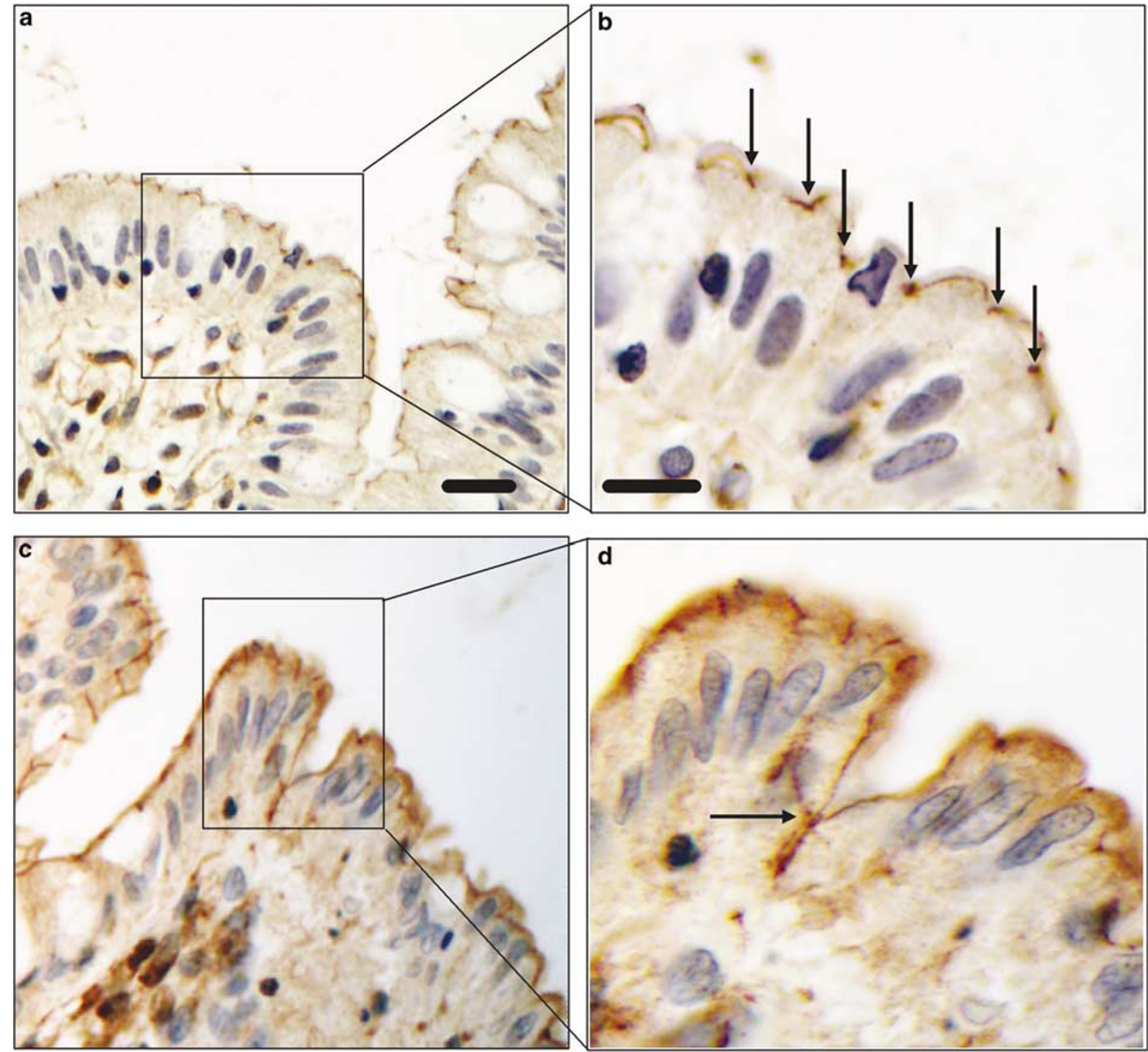

Figure 5 Localization of ZO-1 immunoreactivity following cell shedding. (a and b) ZO-1 immunoreactivity (arrows) at the apical pole of the epithelium adjacent to a shedding cell. (c and d) ZO-1 reactivity at the base of a gap, which is presumed to have been caused by cell shedding. No examples of ZO-1 immunoreactivity beneath the basal pole of a shedding cell were found.

sections remove fragile shedding cells. For the present study, we developed a method for rapidly and gently preparing surgical specimens of small intestine for histology. Important factors for the preservation of cell shedding are minimal handling of the specimen, rapid transfer from the operating theater to the pathology laboratory and a minimal warm ischemia time.

During and after cell shedding, eosin-positive material remains in situ from where the cell was shed. In a previous study of mice we have demonstrated that these sites (termed 'gaps') contain no cellular material but are filled with a substance that maintains the epithelial barrier. ${ }^{12}$ The source and composition of this 'plugging' substance is unknown. Possibilities include material being secreted by neighboring myofibroblasts or the shedding epithelial cell itself. ${ }^{34-36}$ Alternatively, the basement membrane may become infolded or expanded into the gap. In our present study, human epithelial gaps are much less obvious than in our previous confocal microscopy of unfixed living murine intestine. This may be because of shrinkage artefact during fixation, or because gaps are more difficult to identify in fixed sections as eosin stains the material in gaps with approximately the same intensity as cytoplasm, or species differences.

We only counted shedding events from villi that were seen from the side and whose height was twice the width, furthermore greater than $50 \%$ of the villus epithelium was visible as a monolayer of cells. Shedding events on villi that did not fulfill these criteria were not included in our analysis. From our observation of 771 shedding cells from 

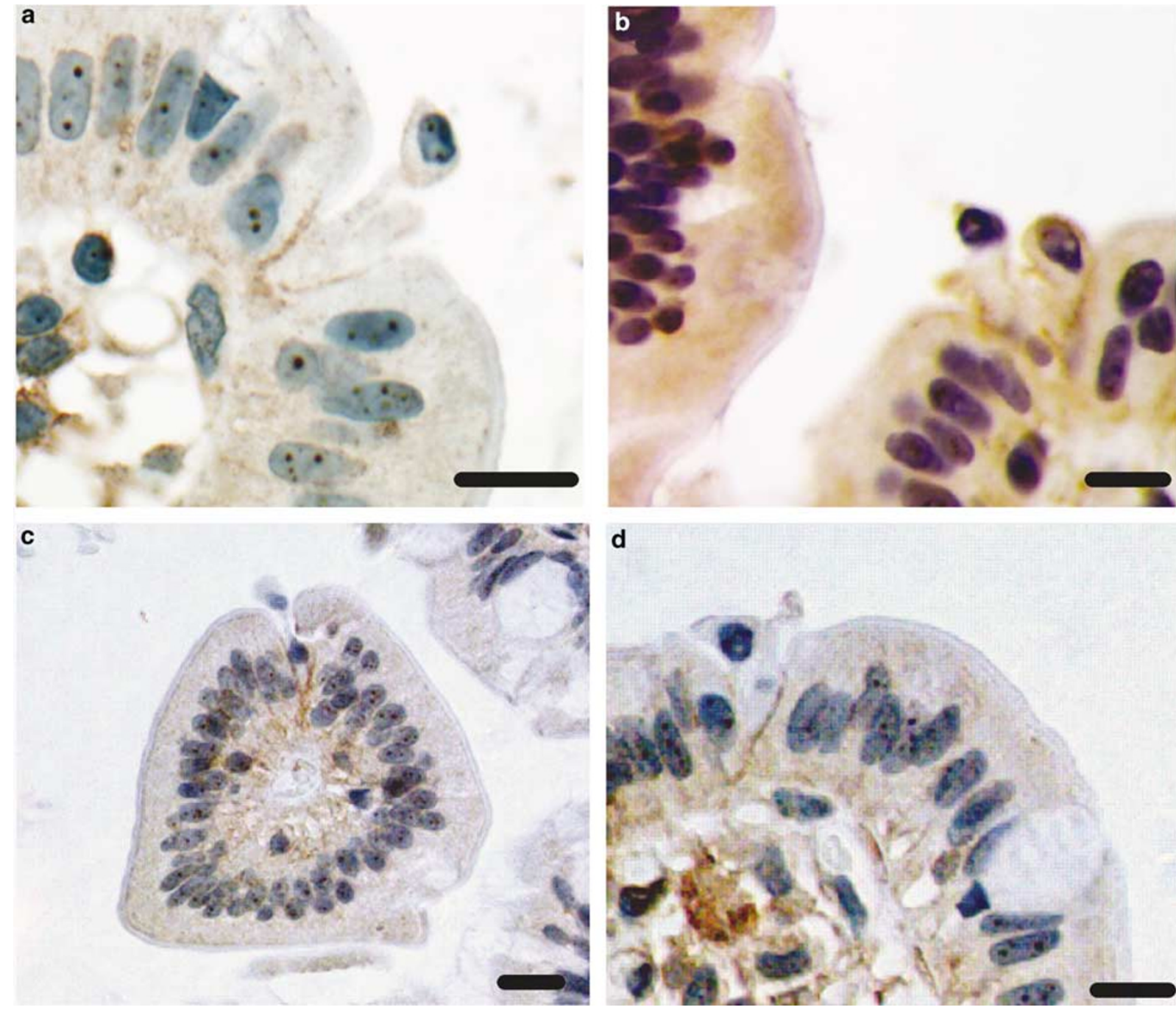

d

Figure 6 MLC phosphorylation occurs at the edge of epithelial cells adjacent to a cell being shed. Four examples are shown (a-d). Bars are $20 \mu \mathrm{m}$.

14417 villus sections (5.35\%) we can crudely estimate our observed rate of cell loss to be 27 cells/villus/24 h. Assuming that villi are circular in cross-section with a $40 \mu \mathrm{m}$ diameter, our $4 \mu \mathrm{m}$ sections which include both sides of the villus, sample approximately $2 \times 4 \mu \mathrm{m} / \pi 40 \mu \mathrm{m}$ of the surface area of the villus. If we also assume it takes 15 min for a cell to be shed, ${ }^{12}$ the observed rate of shedding is $(771 / 14417) \times(\pi 40 / 8) \times(24 \times 4) \mathrm{h}=80$ cells per villus per $24 \mathrm{~h}$. Potten has calculated the rate of cell loss from mouse villi to be 1400 cells/ villus/24 h. ${ }^{1}$ We therefore assume that a substantial number of shedding events are not being seen despite our careful fixation methods, or that other methods of cell replacement (eg phagocytosis) are not being detected by our methods. It is important to bear in mind this calculation assumes those cells are shed at a constant rate equally through the length of the small intestine. If there is clustering of shedding events this calculation may significantly underestimate the total shedding rate. Also, we only define a cell as being in the process of shedding if its nucleus oriented beyond the apical membrane boundary of neighboring cells. It is worth noting that in our previous study we found that $3 \%$ of cell positions were epithelial gaps. If we assume there are 3500 epithelial cells/villus we can calculate that at any time point there are 105 gaps on the villus. If gaps remain for $1 \mathrm{~h}$ before filling in we can calculate there are $105 \times 24 \mathrm{~h}=2500$ shedding events/villus/ $24 \mathrm{~h}$. This is much more in line with the value of Potten of 1400 shedding events $/ 24 \mathrm{~h}$. If we assume gaps exist for $1.8 \mathrm{~h}$ before filling in then our calculated shedding rate becomes identical to that measured by Potten. In the present study, we have only counted shedding marked by a cell leaving the epithelial monolayer. It is likely that there are many gaps without a marking shedding cell that we are unable to identify. This may contribute to the low shedding rate we have calculated. If we assume that all caspase-3-positive cells in the monolayer, irrespective of whether they appear to be shedding or 
not, represent a shedding event we find that 946/865 villus sections contain cleaved caspase-3-positive cells. From this we can calculate shedding rates of 1650 cells are shed per villus per $24 \mathrm{~h}$.

Little is known about the sites along the villus where cells are shed although it is often assumed that all cells are shed from the tip of the villus. ${ }^{5-8}$ Reports using pig intestine or chimeric mice demonstrate that the cohort of cells leaving a crypt often becomes discontinuous (patchy) as cells reach the upper half of the villus, strongly suggesting that significant numbers of cells have been lost from the population at lower regions of the villus. ${ }^{37,38}$ In our own studies, the great majority of shedding events were seen at the villus tip, although we identified one shedding event unequivocally from the shaft of the villus (Figures $4 \mathrm{e}$ and $\mathrm{f}$ ). It is possible that our fixation techniques do not preserve shedding events along the wall of the villus. This may partially account for the low numbers of cell shedding events seen.

The signals initiating cell shedding are unknown but must be robust and accurate as there appears to a tight coupling of cell loss on the villus to cell division in the crypt. Loss of accurate control of cell shedding would presumably cause serious disruption of the mucosal architecture. We wondered whether cells were shed when they came into close proximity with a blood vessel suggesting a blood borne signal such as Netrin- $1^{29}$ but found no evidence for this. To gain further insight into these mechanisms it is important to know whether the target of signalling is apoptosis or some different specific cell shedding mechanism. Extracellular matrix (ECM) molecules provide a constant survival signal to epithelial cells via $\beta_{1}$-integrins, focal adhesion kinase (p125 ${ }^{\mathrm{FAK}}$ ) and protein kinase $\mathrm{B} /$ Akt-1 pathways. ${ }^{31,39}$ Disruption of ECM/integrin interaction causes apoptosis (sometimes called anoikis ${ }^{30}$ ) via the mitochondrial pathway. ${ }^{40}$ Only 3/330 shedding cells were negative for activated caspase-3. Furthermore, we never observe cells in the late stages of apoptosis (apoptotic bodies) in the villus epithelium, unlike the crypt where apoptotic bodies are retained within the epithelial monolayer (Figure 4c). This suggests that the interval between the initiation of shedding and the initiation of apoptosis is very short and can probably not be resolved by immunohistochemical techniques. However, we note that studies of apoptosis in bcl-2, bax and bcl-w knockout mice have found the morphology of the villus tip to be normal in the strains. ${ }^{17,18}$ Thus, if apoptosis is initiating cell shedding, it is by a mechanism independent of these well-known apoptosis molecules.

Our observation that ZO-1 is localized to the apical pole of the immediate neighbors of shedding cells is consistent with our previous observations in living mice where we showed that the site of luminal impermeability is at the apical pole of the epithelium. ${ }^{12}$ Our observation that $50 \%$ of gaps had evidence of phosphorylated MLC at their edge suggests that at least some of the molecular machinery that closes oligocellular wounds in human tissue culture studies is activated. ${ }^{24}$ Together these observations suggest contraction of the actin ring at the apical pole of neighboring epithelial cells to heal gaps by a 'purse string' like mechanism. We speculate that the $50 \%$ of gaps that do not have phosphorylated MLC at their edge may be at an early stage of wound healing before MLC becomes phosphorylated. ROCK is known to be phosphorylated before MLCK but is very transient so unlikely to be seen often. ${ }^{24}$

Our results have implications for intestinal diseases such as Crohn's disease, infective enteritis and graft-versus-host disease where an defective barrier has been implicated in disease pathogenesis. ${ }^{20,41-47}$ Traditionally, the epithelial barrier is believed to have two parts. ${ }^{19}$ One component is the intrinsic impermeability of the epithelial cell apical membrane. The second component is the tight junction between adjacent epithelial cells, which restricts paracellular flux between cells. Both components are subject to regulation, but the tight junction is the logical target when an increase in passive and nonselective flux is required. Regulation of the tight junction complex is a well-established mechanism controlling passive fluxes during sodium and glucose absorption and may be perturbed in inflammatory bowel disease. ${ }^{20,27,47-52}$ We hypothesize that perturbation of the process of cell shedding and the subsequent sealing and healing of resultant gaps in the epithelium may be a pathogenic mechanism. Further studies of cell shedding in Crohn's disease patients are required to investigate these possibilities.

\section{Acknowledgement}

This work was supported by the National Institutes of Health (R01DK61931 and RO1DK68271 to JRT).

\section{References}

1 Potten CS, Loeffler M. Stem cells: attributes, cycles, spirals, pitfalls and uncertainties. Lessons for and from the crypt. Development 1990;110:1001-1020.

2 Watson AJ. Apoptosis and colorectal cancer. Gut 2004;53:1701-1709.

3 Leblond CP, Stevens CE. The constant renewal of the intestinal epithelium in the albino rat. Anatom Rec 1948;100:357-371.

4 Quastler H, Sherman FG. Cell population kinetics in the intestinal epithelium of the mouse. Exp Cell Res 1959;17:420-438.

5 Clarke RM. A new method of measuring the rate of shedding of epithelial cells from the intestinal villus of the rat. Gut 1970;11:1015-1019.

6 Clarke RM. Mucosal architecture and epithelial cell production rate in the small intestine of the albino rat. J Anat 1970;107:519-529. 
7 Heath JP. Epithelial cell migration in the intestine. Cell Biol Int 1996;20:139-146.

8 Montgomery RK, Mulberg AE, Grand RJ. Development of the human gastrointestinal tract: twenty years of progress. Gastroenterology 1999;116:702-731.

9 Mayhew TM, Myklebust R, Whybrow A, et al. Epithelial integrity, cell death and cell loss in mammalian small intestine. Histol Histopathol 1999; 14:257-267.

10 Potten CS, Allen TD. Ultrastructure of cell loss in intestinal mucosa. J Ultrastruct Res 1977;60:272-277.

11 Grossmann J, Mohr S, Lapentina EG, et al. Sequential and rapid activation of select caspases during apoptosis of normal intestinal epithelial cells. Am J Physiol 1998;274(6 Part 1):G1117-G1124.

12 Watson A, Chu S, Sieck L, et al. Epithelial barrier function in vivo is sustained despite gaps in epithelial layers. Gastroenterology 2005;129:902-912.

13 Iwanaga T, Han H, Adachi K, et al. A novel mechanism for disposing of effete epithelial cells in the small intestine of guinea pigs. Gastroenterology 1993;105: 1089-1097.

14 Myklebust R, Mayhew TM. Further evidence of species variation in mechanisms of epithelial cell loss in mammalian small intestine: ultrastructural studies on the reindeer (Rangifer tarandus) and seal (Phoca groenlandica). Cell Tissue Res 1998;291: 513-523.

15 Hall PA, Coates PJ, Ansari B, et al. Regulation of cell number in the mammalian gastrointestinal tract: the importance of apoptosis. J Cell Sci 1994;107(Part 12):3569-3577.

16 Merritt AJ, Potten CS, Watson AJ, et al. Differential expression of bcl-2 in intestinal epithelia. Correlation with attenuation of apoptosis in colonic crypts and the incidence of colonic neoplasia. J Cell Sci 1995;108(Part 6):2261-2271.

17 Pritchard DM, Print C, O'Reilly L, et al. Bcl-w is an important determinant of damage-induced apoptosis in epithelia of small and large intestine. Oncogene 2000;19:3955-3959.

18 Pritchard DM, Potten CS, Korsmeyer SJ, et al. Damageinduced apoptosis in intestinal epithelia from bcl-2null and bax-null mice: investigations of the mechanistic determinants of epithelial apoptosis in vivo. Oncogene 1999;18:7287-7293.

19 Montrose MH. The future of GI and liver research: editorial perspectives: I. Visions of epithelial research. Am J Physiol Gastrointest Liver Physiol 2003;284: G547-G550.

20 Clayburgh DR, Shen L, Turner JR. A porous defense: the leaky epithelial barrier in intestinal disease. Lab Invest 2004;84:282-291.

21 Florian P, Schoneberg T, Schulzke JD, et al. Single-cell epithelial defects close rapidly by an actinomyosin purse string mechanism with functional tight junctions. J Physiol 2002;545(Part 2):485-499.

22 Rosenblatt J, Raff MC, Cramer LP. An epithelial cell destined for apoptosis signals its neighbors to extrude it by an actin- and myosin-dependent mechanism. Curr Biol 2001;11:1847-1857.

23 Bement WM, Forscher P, Mooseker MS. A novel cytoskeletal structure involved in purse string wound closure and cell polarity maintenance. J Cell Biol 1993;121:565-578.

24 Russo JM, Florian P, Shen L, et al. Distinct temporalspatial roles for rho kinase and myosin light chain kinase in epithelial purse-string wound closure. Gastroenterology 2005;128:987-1001.

25 Bancroft JD, Gamble M. Theory and Practice of Histological Techniques, 5th edn. London: Churchill Livingstone, 2002.

26 Marshman E, Ottewell PD, Potten CS, et al. Caspase activation during spontaneous and radiation-induced apoptosis in the murine intestine. J Pathol 2001; 195:285-292.

27 Berglund JJ, Riegler M, Zolotarevsky Y, et al. Regulation of human jejunal transmucosal resistance and MLC phosphorylation by Na+-glucose cotransport. Am J Physiol Gastrointest Liver Physiol 2001;281: G1487-G1493.

28 Caulin C, Salvesen GS, Oshima RG. Caspase cleavage of keratin 18 and reorganization of intermediate filaments during epithelial cell apoptosis. J Cell Biol 1997;138:1379-1394.

29 Mazelin L, Bernet A, Bonod-Bidaud C, et al. Netrin-1 controls colorectal tumorigenesis by regulating apoptosis. Nature 2004;431:80-84.

30 Frisch SM, Francis H. Disruption of epithelial cellmatrix interactions induces apoptosis. J Cell Biol 1994;124:619-626.

31 Dufour G, Demers MJ, Gagne D, et al. Human intestinal epithelial cell survival and anoikis. Differentiation state-distinct regulation and roles of protein kinase B/Akt isoforms. J Biol Chem 2004;279:44113-44122.

32 Leers MP, Kolgen W, Bjorklund V, et al. Immunocytochemical detection and mapping of a cytokeratin 18 neo-epitope exposed during early apoptosis. J Pathol 1999;187:567-572.

33 Madara JL. Maintenance of the macromolecular barrier at cell extrusion sites in intestinal epithelium: physiological rearrangement of tight junctions. J Membr Biol 1990;116:177-184.

34 Fritsch C, Simon-Assmann P, Kedinger M, et al. Cytokines modulate fibroblast phenotype and epithelial-stroma interactions in rat intestine. Gastroenterology 1997;112:826-838.

35 Mahida YR, Beltinger J, Makh S, et al. Adult human colonic subepithelial myofibroblasts express extracellular matrix proteins and cyclooxygenase-1 and -2. Am J Physiol 1997;273(6 Part 1):G1341-G1348.

36 Powell DW, Mifflin RC, Valentich JD, et al. Myofibroblasts. II. Intestinal subepithelial myofibroblasts. Am J Physiol 1999;277(2 Part 1):C183-C201.

37 Schmidt GH, Garbutt DJ, Wilkinson MM, et al. Clonal analysis of intestinal crypt populations in mouse aggregation chimaeras. J Embryol Exp Morphol 1985; 85:121-130.

38 Smith MW, Jarvis LG. Growth and cell replacement in the new-born pig intestine. Proc R Soc Lond B Biol Sci 1978;203:69-89.

39 Strater J, Wedding U, Barth TF, et al. Rapid onset of apoptosis in vitro follows disruption of beta 1-integrin/ matrix interactions in human colonic crypt cells. Gastroenterology 1996;110:1776-1784.

40 Valentijn AJ, Metcalfe AD, Kott J, et al. Spatial and temporal changes in Bax subcellular localization during anoikis. J Cell Biol 2003;162:599-612.

41 Katz KD, Hollander D, Vadheim CM, et al. Intestinal permeability in patients with Crohn's disease and their healthy relatives. Gastroenterology 1989;97:927-931.

42 Fegan C, Poynton CH, Whittaker JA. The gut mucosal barrier in bone marrow transplantation. Bone Marrow Transplant 1990;5:373-377. 
43 Yuhan R, Koutsouris A, Savkovic SD, et al. Enteropathogenic Escherichia coli-induced myosin light chain phosphorylation alters intestinal epithelial permeability. Gastroenterology 1997;113:1873-1882.

44 Irvine EJ, Marshall JK. Increased intestinal permeability precedes the onset of Crohn's disease in a subject with familial risk. Gastroenterology 2000;119: 1740-1744.

45 Berkes J, Viswanathan VK, Savkovic SD, et al. Intestinal epithelial responses to enteric pathogens: effects on the tight junction barrier, ion transport, and inflammation. Gut 2003;52:439-451.

46 Buhner S, Buning C, Genschel J, et al. Genetic basis for increased intestinal permeability in families with Crohn's disease: role of CARD15 3020insC mutation? Gut 2006;55:342-347.

47 Schreiber S, Rosenstiel P, Albrecht M, et al. Genetics of Crohn's disease, an archetypal inflammatory barrier disease. Nat Rev Genet 2005;6:376-388.
48 Oshitani N, Watanabe K, Nakamura S, et al. Dislocation of tight junction proteins without F-actin disruption in inactive Crohn's disease. Int J Mol Med 2005;15:407-410.

49 Gassler N, Rohr C, Schneider A, et al. Inflammatory bowel disease is associated with changes of enterocytic junctions. Am J Physiol Gastrointest Liver Physiol 2001;281:G216-G228.

50 Suenaert P, Bulteel V, Lemmens L, et al. Anti-tumor necrosis factor treatment restores the gut barrier in Crohn's disease. Am J Gastroenterol 2002;97:20002004.

51 Turner JR, Rill BK, Carlson SL, et al. Physiological regulation of epithelial tight junctions is associated with myosin light-chain phosphorylation. Am J Physiol 1997;273(4 Part 1):C1378-C1385.

52 Macdonald TT, Monteleone G. Immunity, inflammation, and allergy in the gut. Science 2005;307: 1920-1925. 